This study was conducted at the Medical Research Council Epidemiology Unit, Cardiff. The support of Professor Gray, Robert Newcombe, and the lactation nurse is acknowledged.

\author{
References \\ ${ }^{1}$ Sloper K, McKean L, Baum JD. Factors influencing breast- \\ feeding. Arch Dis Child 1975;50:165. \\ 2 Department of Health and Social Security. Present day practice \\ in infant feeding. Report on Health and Social Subjects. \\ London: HMSO, 1974.
}

${ }^{3}$ Grosvenor P. Influences affecting mothers' decisions about infant feeding. (Thesis). Edinburgh, 1969.

${ }^{4}$ Newson J, Newson E. Infant care in an urban community. London: George Allen and Unwin, 1963.

5 Martin J. Infant feeding 1975: attitudes and practice in England and Wales. OPCS Social Survey Division. London: HMSO, 1978.

Correspondence to Dr D A Jones, Research Team for Care of Elderly, Welsh National School of Medicine, Cardiff CF4 4XN.

Received 15 March 1985

\title{
Pathogenesis of liver damage during parenteral nutrition: is lipofuscin a clue?
}

\author{
H M BERGER, A L DEN OUDEN, AND J J CALAME \\ Departments of Pediatrics and Pathology, University Hospital Leiden, The Netherlands
}

SUMmary Lipofuscin develops in cells when peroxidation damage occurs. Its development in the liver of patients receiving prolonged parenteral nutrition suggests that peroxidation damage by free radicals has occurred. Deficiencies in antioxidants such as vitamin $\mathrm{E}$ may be an important contributing factor.

Peroxidation damage by free radicals can cause disease of the liver-for example, carbon tetrachloride poisoning ${ }^{1}$ and alcoholic cirrhosis. ${ }^{2}$ The pathogenesis of the damage to the liver in patients receiving parenteral nutrition is unknown. Lipofuscin found often in hepatic cells may be an important clue. Lipofuscin, a complex of lipids, proteins, and malonaldehyde, develops when subcellular membranes are damaged by peroxidation of free radicals. ${ }^{13}$

\section{Case report}

A $930 \mathrm{~g}$ girl was born at 27 weeks' gestation after her mother had developed amnionitis. She was electively ventilated and treated for pneumonia with intravenous ampicillin and gentamicin for 14 days. No bacteria were cultured, and on day 10 treatment with intravenous fluorocytosine and amphotericin were started after Candida albicans had been cultured in urine obtained by bladder puncture. Continuous positive airway pressure was required for recurrent apnoeic attacks.

Cardiac failure developed due to a patent ductus arteriosus. This did not respond to fluid restriction or treatment with frusemide and indomethacin, and surgical ligation was performed (on day 60).

The baby received total parenteral nutrition for the first 20 days. Repeated attempts to introduce expressed mother's milk or formula feeds failed, and a further 40 days of total or partial parenteral feeding was needed. The regimen $(150 \mathrm{ml}, 372$ $\mathrm{KJ} / \mathrm{Kg} / 24$ hours) included $7 \%$ Vamin (Kabivitrum, Stockholm, Sweden) $(30 \mathrm{ml} / \mathrm{Kg} / 24$ hours $)$ and $10 \%$ Intralipid (Kabivitrum, Stockholm, Sweden) (30 $\mathrm{ml} / \mathrm{Kg} / 24$ hours) with added fat soluble vitamins $\mathrm{A}$, $D$, and K (Vitalipid; Kabivitrum, Stockholm, Sweden). Water soluble vitamins and trace elements were added to the $10 \%$ glucose and electrolyte infusion. Enteral vitamin E (alpha tocopherol acetate, $10 \mathrm{mg} / \mathrm{Kg} / 24$ hours) was given when milk feeds were tolerated.

The initial physiological jaundice (highest level on day 5; total serum bilirubin concentration 181 $\mu \mathrm{mol} / \mathrm{l}$; and conjugated bilirubin concentration 14 $\mu \mathrm{mol} / \mathrm{l})$ resolved after phototherapy. On day 30 the baby developed cholestatic jaundice with a $2 \mathrm{~cm}$ hepatomegaly. The bilirubin (total concentration $200 \mu \mathrm{mol} / \mathrm{l}$, conjugated bilirubin concentration 164 $\mu \mathrm{mol} / \mathrm{l})$, serum aspartate transaminase (122 U/l), and serum alainine transaminase $(42 \mathrm{U} / \mathrm{l})$ concentrations had increased. Serology showed no evidence of infection-for example with cytomegalovirus. The serum $\alpha_{1}$ antitrypsin concentration and concentration of chloride in sweat were normal, and no reducing substances were present in the urine when the baby was given milk feeds. Ultrasound study of the liver and biliary tree showed normal 
findings. A low plasma vitamin $\mathrm{E}$ concentration $(10.4 \mu \mathrm{mol} / \mathrm{l})$ was found on day 28.

A percutaneous needle biopsy of the liver was performed (day 60). The architecture of the liver was normal on light microscopy. Stains with haematoxylin and eosin showed a yellow brown lipofuscin like pigment in some of the Kupffer cells but not in the hepatocytes. Kupffer cells and hepatocytes contained periodic acid Schiff positive granules resistant to digestion by diastase, suggestive of the lipofuscin pigment found after parenteral feeding. ${ }^{4}$ Bile pigment was present in the hepatocytes and dilated canaliculi.

Electron microscopy showed phagolysosomal structures within the cytoplasm of the Kupffer cells and hepatocytes (Figure (a) and (b)). These structures, enveloped by a single limiting membrane, contained partly electron dense, and partly electron lucent granular material. Electron lucent vacuoles, well developed in the Kupffer cells, were also present. These lysosomal structures are compatible with lipofuscin. ${ }^{3}$

The cholestatic jaundice was as a result of its typical course and exclusion of other causes considered to be related to the parenteral nutrition. The liver dysfunction rapidly resolved when complete nasoduodenal feeding was tolerated after day 100 . At 2 years of age the child was growing and developing normally and had no evidence of liver disease.

\section{Discussion}

Histochemical and ultrastructural studies have suggested that the granules of pigment seen in the liver after parenteral nutrition are lipofuscin. ${ }^{45}$ The electron microscopic features we found are further evidence $^{3}$ to support those finding.

Previously, the accumulation of this pigment in subjects was considered to be a complication of receiving fat emulsions ('intravenous fat pigment'). ${ }^{6}$ As the damage to the liver also occurs when no fat emulsion has been used the presence of lipofuscin has not been linked to the pathogenesis of the disease. When we reviewed previous reports, however, we found that lipofuscin had been found in the liver even when only amino acid and glucose electrolyte mixtures had been infused. ${ }^{45}$ Cohen and Olsen detected lipofuscin in $90 \%$ of their babies, though only $35 \%$ had received fat emulsion. ${ }^{4}$

There is a powerful antioxidant defence system in man-for example, enzymes such as glutathione peroxidase and free radical scavengers such as vitamin E. ${ }^{1}$ Nutritional deficiencies-for example, in selenium and vitamin E-that develop with parenteral feeding could weaken the antioxidant
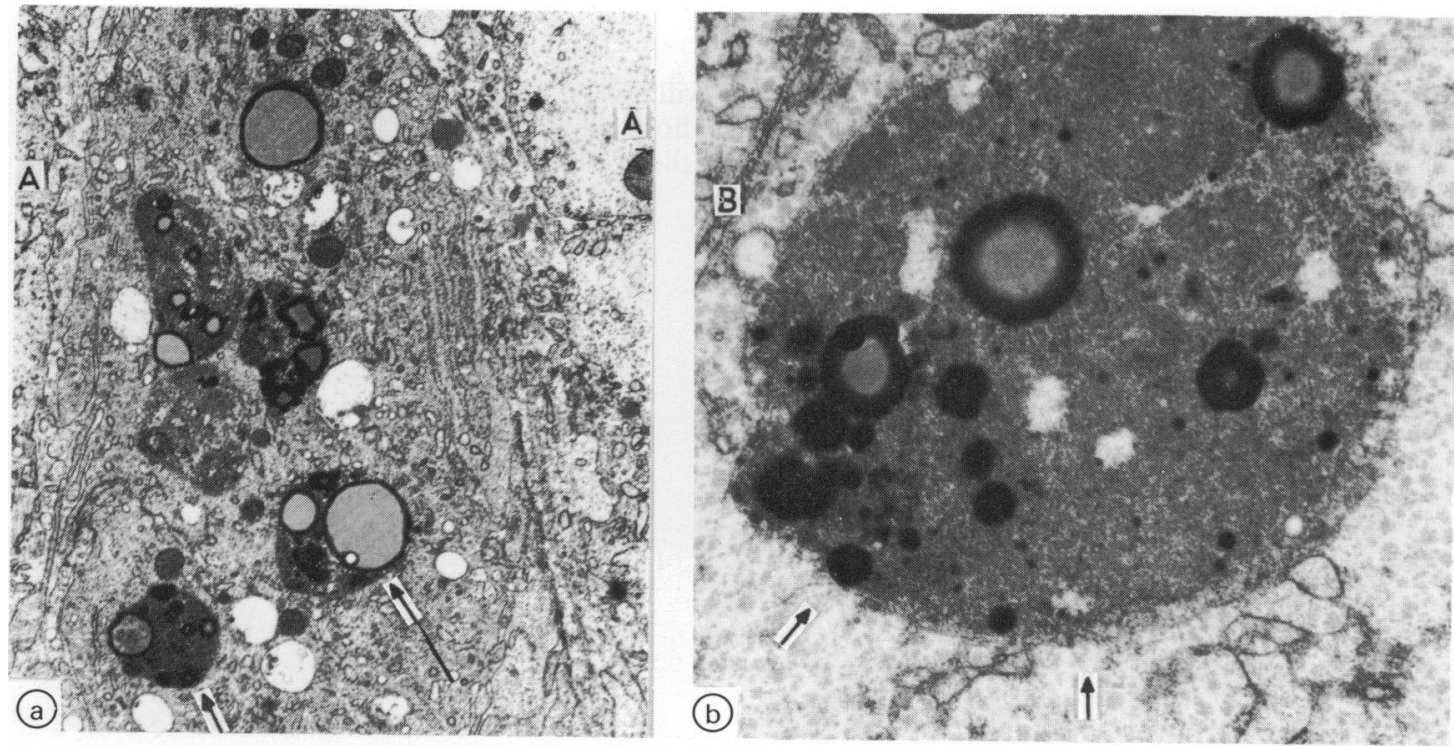

Figure (a) The Kupffer cell between two hepatocytes $(A)$ contains intracytoplasmic structures (arrows), which resemble lipofuscin granules. $\times 9200$ (original magnification). (b) Lipofuscin granule in a hepatocyte. Borders (B) of the cell and an adjacent hepatocyte are shown. $\times 26000$ (original magnification). 
defences and allow damage by free radicals. The vitamin mixtures that we added to the intravenous solutions did not contain vitamin E, and Intralipid contains only inactive gamma tocopherol. Our patient did have a low plasma vitamin E concentration when damage to the liver became evident.

The aetiology of cholestatic jaundice after parenteral feeding is not known. The presence of lipofuscin in the hepatic cells suggests that peroxidation damage by free radicals plays a part in the pathogenesis of this disease. Investigation into the role of damage by free radicals is indicated as it may be possible to prevent this disease by antioxidant treatment.

We thank Professor Kenneth R Brizzee, Delta Regional Primate Research Center, Louisiana, United States of America, for his suggestions on the interpretation of the electron microscopic findings.

\section{References}

${ }^{1}$ Dormandy TL. An approach to free radicals. Lancet 1983;ii:1011-4.

${ }^{2}$ Lewis KO, Paton A. Could superoxide cause cirrhosis? Lancet 1982;ii:188-9.

${ }^{3}$ Brizzee KR, Ordy JM. Cellular features, regional accumulation, and prospects of modification of age pigments in mammals. In: Sohal RS, ed. Age pigments. Amsterdam: Elsevier Biomedical Press, 1981:101-54.

${ }^{4}$ Cohen C, Olsen MM. Pediatric total parenteral nutrition, liver histopathology. Arch Pathol Lab Med 1981;105:152-6.

${ }^{5}$ Bernstein J, Chang CH, Brough AJ, Heidelberger KP. Conjugated hyperbilirubinemia in infancy associated with parenteral alimentation. J Pediatr 1977;90:361-7.

${ }^{6}$ Koga Y, Swanson VL, Hays DM. Hepatic 'intravenous fat pigment' in infants and children receiving lipid emulsion. J Pediatr Surg 1975;10:641-8.

Correspondence to Dr H M Berger, Department of Paediatrics, University Hospital Leiden, 2333 AA Leiden, The Netherlands.

Received 22 April 1985

\section{Shredding of manuscripts}

From 1 January 1986 articles submitted for publication will not be returned if the paper is rejected unless this is requested at the time of submission. Authors whose papers are rejected will be advised of the decision; the manuscripts will be kept under security for three months to deal with any enquiries and then destroyed by shredding. 